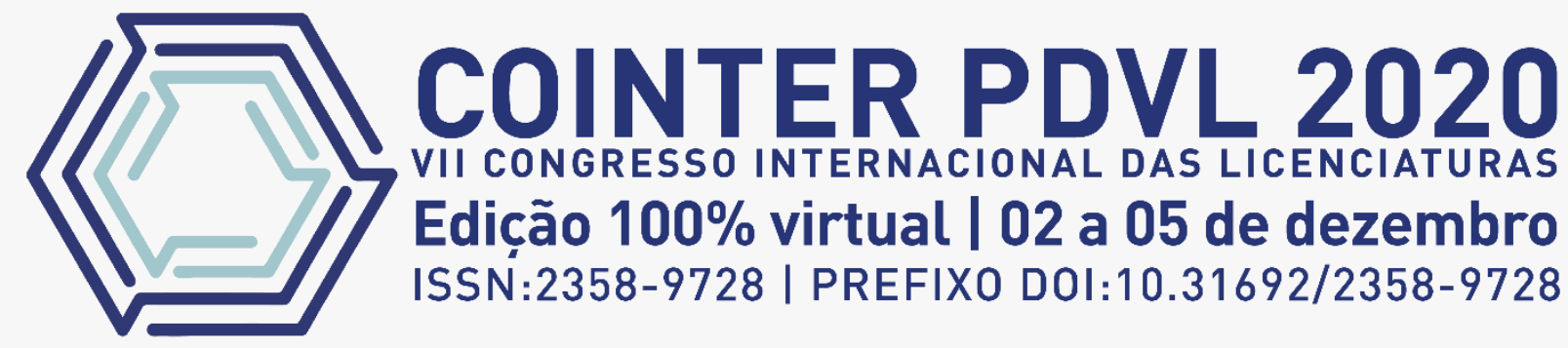

\title{
CONHECIMENTOS PEDAGÓGICOS NA EDUCAÇÃO FINANCEIRA ESCOLAR: DISCIPLINAS, CONTEÚDOS E TRANSVERSALIDADE
}

\author{
CONOCIMIENTOS PEDAGÓGICOS EN LA EDUCACIÓN FINANCIERA \\ ESCOLAR: DISCIPLINAS, CONTENIDOS Y TRANSVERSALIDAD
}

\section{PEDAGOGICAL KNOWLEDGE IN SCHOOL FINANCIAL EDUCATION: DISCIPLINES, CONTENTS AND TRANSVERSALITY}

\author{
Apresentação: Comunicação Oral \\ Autora: Fabiana Gomes da Silva ${ }^{1}$; Orientadora: Cristiane Azêvedo dos Santos Pessoa ${ }^{2}$
}

DOI:https://doi.org/10.31692/2358-9728.VIICOINTERPDVL.0043

\begin{abstract}
RESUMO
O presente artigo é fruto de um recorte de um estudo maior, em andamento. Este artigo tem por objetivo analisar Conhecimentos Pedagógicos de Educação Financeira de professores que ensinam matemática no $3^{\circ}$ ano do Ensino Fundamental. Especificamente objetiva analisar qual ou quais disciplinas e conteúdos podem, na visão de professores, trabalhar o tema EF; e discutir sobre a tranversalidade do tema e as possíveis relações com conteúdos matemáticos. Para isso, foram entrevistadas duas professoras do $3^{\circ}$ ano do Ensino Fundamental. Como aporte teórico utilizamos a Mathematical Knowledge for Teaching (MKT) de Ball, Thames Phelps (2008) e Tardif e Raymond (2000). A pesquisa é de abordagem qualitativa e apresenta como principais resultados que as professoras utilizaram a experiência docente para relacionar possíveis conteúdos e disciplinas ao tema, o que nos remete aos Conhecimentos Pedagógicos do Conteúdo, como o conhecimento de conteúdo e ensino, quando escolhem abordagens apropriadas para o conteúdo, conhecimento de conteúdo e aluno quando procuram adequar o ensino à realidade vivenciada pelo aluno e ainda, o conhecimento curricular, quando reconhecem conteúdos e atividades adequadas ao ano escolar por meio de livros e materiais didáticos escolares. Como principais conclusões salientamos a importância da formação de professores no intuito de ampliar e trazer à consciência os conhecimentos para o ensino de uma EF crítica, reflexiva e contextualizada. Além da formação docente, é necessário formar coordenadores pedagógicos para trabalharem com os seus professores e viabilizarem as ações, pois, a abordagem desta temática encontra-se nos documentos oficiais, como a Base Nacional Comum Curricular BNCC (BRASIL, 2017), que estabelecem os conteúdos e temáticas que as escolas de todo o país devem adotar.

Palavras-Chave: Educação Financeira Escolar, Anos Iniciais do Ensino Fundamental, Mathematical Knowledge for Teaching.
\end{abstract}

\section{RESUMEN}

${ }^{1}$ Mestranda em Educação Matemática e Tecnológica (PPGEdumatec), Universidade Federal de Pernambuco (UFPE), fabianaeducacao417@gmail.com

${ }^{2}$ Doutora em Educação, pesquisadora e professora da Pós-graduação em Educação Matemática e Tecnológica (PPGEdumatec), UFPE. cristiane.pessoa@ufpe.br 
Este artículo es el resultado de una sección de un estudio más amplio, en curso. Este artículo tiene como objetivo analizar el Conocimiento Pedagógico de la Educación Financiera de los docentes que imparten matemáticas en el $3^{\circ}$ año de Educación Primaria. En concreto, se pretende analizar qué o qué disciplinas y contenidos pueden, en opinión de los profesores, trabajar sobre el tema EF; y discutir la transversalidad del tema y las posibles relaciones con el contenido matemático. Para ello, se entrevistó a dos profesores de $3^{\circ}$ año de primaria. Como contribución teórica se utilizó el Conocimiento Matemático para la Enseñanza (MKT) de Ball, Thames Phelps (2008) y Tardif y Raymond (2000). La investigación tiene un enfoque cualitativo y presenta como principales resultados que los docentes utilizaron la experiencia docente para relacionar posibles contenidos y disciplinas con la temática, lo que nos lleva al Conocimiento Pedagógico de los Contenidos, como el conocimiento de contenidos y la docencia, al elegir enfoques adecuados para el contenido, el conocimiento de los contenidos y el alumno cuando intentan adecuar la enseñanza a la realidad vivida por el alumno y también, los conocimientos curriculares, cuando reconocen contenidos y actividades adecuadas para el curso escolar a través de los libros de texto y materiales escolares. Como principales conclusiones destacamos la importancia de la formación del profesorado con el fin de ampliar y sensibilizar a la enseñanza de una EF crítica, reflexiva y contextualizada. Además de la formación docente, es necesario formar coordinadores pedagógicos para trabajar con sus docentes y viabilizar acciones, ya que el abordaje de esta temática se encuentra en documentos oficiales, como la Base Curricular Común Nacional - BNCC (BRASIL, 2017), que establecen el contenido y los temas que deben adoptar las escuelas de todo el país.

Palabras Clave:Educación Financiera Escolar, Primeros Años de la Escuela Primaria, Mathematical Knowledge for Teaching.

\section{ABSTRACT}

This article is the result of a section of a larger study, in progress. This article aims to analyze Pedagogical Knowledge of Financial Education of teachers who teach mathematics in the 3rd year of Elementary School. Specifically, it aims to analyze which or which disciplines and contents can, in the view of teachers, work on the theme EF; and discuss the transversality of the theme and the possible relationships with mathematical content. For this, two teachers from the 3rd year of elementary school were interviewed. As a theoretical contribution, we used the Mathematical Knowledge for Teaching (MKT) by Ball, Thames Phelps (2008) and Tardif and Raymond (2000). The research has a qualitative approach and presents as main results that the teachers used the teaching experience to relate possible contents and disciplines to the theme, which brings us to the Pedagogical Knowledge of Content, such as knowledge of content and teaching, when choosing appropriate approaches for the content, content knowledge and student when they try to adapt the teaching to the reality experienced by the student and also, the curricular knowledge, when they recognize content and activities suitable for the school year through school textbooks and materials. As main conclusions we emphasize the importance of teacher training in order to expand and bring awareness to the teaching of a critical, reflective and contextualized PE. In addition to teacher training, it is necessary to train pedagogical coordinators to work with their teachers and make actions feasible, since the approach to this theme is found in official documents, such as the Common Curricular National Base - BNCC (BRASIL, 2017), which establish the content and themes that schools across the country must adopt.

Keywords: School Financial Education, Early Years of Elementary School, Mathematical Knowledge for Teaching.

\section{INTRODUÇÃO}

\section{Mundialmente a Organização para Cooperação e Desenvolvimento Econômico} (OCDE) discute com países membros e países colaboradores, entre outros aspectos, estratégias, boas práticas e fazem recomendações sobre a abordagem da Educação Financeira (EF) para a população. A OCDE formulou uma definição de EF que serve de base para diversos países instituírem suas estratégias de educação financeira, que é a seguinte: 
O processo mediante o qual os indivíduos e as sociedades melhoram sua compreensão dos conceitos e dos produtos financeiros, de maneira que, com informação, formação e orientação claras, adquiram os valores e as competências necessários para se tornarem conscientes das oportunidades e dos riscos neles envolvidos e, então, façam escolhas bem informados, saibam onde procurar ajuda, adotem outras ações que melhorem o seu bem-estar, contribuindo, assim, de modo consistente para formação de indivíduos e sociedades responsáveis, comprometidos com o futuro (OCDE, 2005, p.3).

No Brasil foi criada a Estratégia Nacional de Educação Financeira (ENEF) a partir das recomendações da OCDE, por meio do Decreto 7.397 em dezembro de 2010 com o objetivo de orientar a população, de forma gratuita, por meio de ações executadas pela AEF-Brasil e outros parceiros, assim como por meio de materiais didáticos que podem ser encontrados em seu site Vida e dinheiro. Com a renovação da ENEF através do Decreto Federal no 10.393, de junho de 2020, a coordenação passa a ser o Fórum Brasileiro de Educação Financeira (FBEF).

A EF pode se apresentar de diversas perspectivas e a partir da visão de diferentes áreas, como nas Ciências Econômicas, nas Ciências Contábeis, na Administração, na Psicologia e na Educação. Embora algumas escolas já abordassem de alguma forma em seu currículo, como um diferencial, foi com a homologação da Base Nacional Comum Curricular - BNCC (BRASIL, 2017) que a EF na escola passou a ser obrigatória em todo o Ensino Básico, tratando-se de um tema transversal. Para o presente artigo abordaremos a Educação Financeira Escolar (EFE), conceito cunhado por Silva e Powell (2013) que fundamentam que a EF deve ser trabalhada em sala de aula nos aspectos críticos, matemáticos e políticos.

De modo semelhante, Pessoa (2016) fundamenta que o estudo da EF

\begin{abstract}
facilite o desenvolvimento de reflexões críticas e proporcione aos alunos uma aprendizagem mais contextualizada e significativa, tendo em vista que a Matemática, além de fazer parte da realidade, também pode ser capaz de intervir na mesma. A EF tem por propósito, dentre outros objetivos, ajudar as pessoas a administrarem seu dinheiro e o que ele envolve, poupança, finanças, cartões de crédito, investimentos, compras, vendas, por exemplo. Além do auxílio na administração do dinheiro, acreditamos também no papel da EF de propiciar a discussão acerca de um consumo consciente, da influência que a mídia exerce nas escolhas diárias, da reflexão sobre o que desejamos e o que realmente precisamos, sobre o impacto ambiental que algumas escolhas podem causar etc. Quanto mais a sociedade se complexifica, mais necessário é o domínio do conhecimento financeiro das pessoas de qualquer nível socioeconômico, que compõem a sociedade (PESSOA, 2016, p. 241-242).
\end{abstract}

Para abordar o tema em sala de aula, que embora se apresente em apenas algumas habilidades da BNCC, é necessário que o professor desenvolva estratégias em suas aulas para trazer o tema de forma contextualizada e reflexiva.

Silva, Pessoa e Carvalho (2019) realizaram uma pesquisa com oito pedagogas que lecionavam no $3^{\circ}$ ano do Ensino Fundamental e, entre outros aspectos, constataram que as docentes confundiam o ensino de EF com o ensino do conteúdo sistema monetário. 
Salientamos que, embora possam ser trabalhados juntos, o ensino de EF é diferente do ensino do sistema monetário. O primeiro abrange diversos conteúdos e áreas do conhecimento e o segundo aborda aspectos da moeda nacional e alguns de seus usos e é nesses usos do dinheiro que podemos explorar o tema EF.

Dessa forma, já que a EF abrange diversos conteúdos e áreas do conhecimento, pode então surgir as questões: na visão de professores, em quais disciplinas e conteúdos a EF pode ser abordada? Os professores conhecem a transversalidade da temática EF e como desenvolvê-la em sala de aula?

Objetivando responder essas questões, buscamos, no presente artigo, analisar Conhecimentos Pedagógicos de Educação Financeira de professores que ensinam matemática no $3^{\circ}$ ano do Ensino Fundamental. Especificamente objetivamos analisar qual ou quais disciplinas e conteúdos podem, na visão de professores, trabalhar o tema EF; e discutir sobre a transversalidade do tema e as possíveis relações com conteúdos matemáticos.

Para uma melhor compreensão da discussão aqui proposta, dividimos esse artigo em introdução, na qual abordamos contextos iniciais de EF, nossas questões norteadoras e objetivos. A fundamentação teórica na qual apresentamos a definição de saberes da experiência proposto por Tardif e Raymond (2000) e apresentamos também Ball, Thames e Phelps (2008), que definem a teoria Mathematical Knowledge for Teaching (MKT), na qual focaremos na dimensão pedagógica do conteúdo. Em seguida apresentamos o método deste estudo, seguido dos resultados e discussões em que apresentamos a visão das professoras entrevistadas sobre quais disciplinas e conteúdos abordar quando se ensina EF, entre outros aspectos. Por fim, apresentamos as considerações finais em que retomamos as principais discussões do presente artigo, apresentamos algumas conclusões e sugerimos alguns encaminhamentos. Dessa forma, a seguir apresentamos nossa fundamentação teórica.

\section{FUNDAMENTAÇÃO TEÓRICA}

Para a construção da identidade do professor, há uma longa caminhada. Tardif e Raymond (2000) apontam alguns desses passos. Para os autores, a atividade docente modifica a identidade, assim como modifica o saber próprio do seu trabalho. Para cada atividade profissional é necessário domínio teórico e técnico, para atividade docente não é diferente, no entanto é durante a prática docente que alguns saberes se originam e dão sentido na conjuntura do trabalho, portanto os autores defendem que esses saberes são temporais, pois são estruturados em um determinado tempo que varia de acordo com cada trabalho. Em pesquisa na literatura, os autores apontam que parte da literatura norte americana propunha os 
saberes que servem como base para o ensino, denominando-o de Knowledge base.

Os autores explicam que essa expressão pode ser compreendida no sentido restrito, quando é correspondido à ação em sala de aula do competente professor, são saberes que normalmente são incorporados nos programas de formação docente. Já no sentido amplo, são saberes que respaldam o exercício do ensino, oriundos de diversas fontes, como a própria socialização do professor, formações diversas, a própria experiência e de colegas. É nesse sentido mais amplo que os autores atribuem à sua concepção. $\mathrm{O}$ posicionamento de Tardif e Raymond (2000) como eles mesmos descrevem, está de acordo com o que os próprios professores dizem a respeito de seus saberes.

Dessa forma, os autores tecem uma crítica à base de ensino que defende o conhecimento do conteúdo especializado, pois, de acordo com a observação por eles realizada, a base para o ensino não se limita apenas ao conhecimento do conteúdo de forma especializada, mas, segundo os autores os saberes são diversos e de diversas fontes, conforme mostra o Quadro 1 a seguir.

Quadro 1: Os saberes dos professores

\begin{tabular}{|c|c|c|}
\hline $\begin{array}{l}\text { SABERES DOS } \\
\text { PROFESSORES }\end{array}$ & $\begin{array}{l}\text { FONTES SOCIAIS DE } \\
\text { AQUISIÇÃO }\end{array}$ & MODOS DE INTEGRAÇÃO \\
\hline $\begin{array}{l}\text { Saberes pessoais dos } \\
\text { professores }\end{array}$ & $\begin{array}{l}\text { Família, ambiente de vida, a } \\
\text { educação no sentido lato etc. }\end{array}$ & $\begin{array}{l}\text { Pela história de vida e pela } \\
\text { socialização primária }\end{array}$ \\
\hline $\begin{array}{l}\text { Saberes provenientes da } \\
\text { formação escolar }\end{array}$ & $\begin{array}{l}\text { A escola primária e secundária, } \\
\text { os estudos pós secundários não } \\
\text { especializados etc. }\end{array}$ & $\begin{array}{c}\text { Pela formação e pela } \\
\text { socialização pré-profissionais }\end{array}$ \\
\hline $\begin{array}{c}\text { Saberes provenientes da } \\
\text { formação profissional para o } \\
\text { magistério }\end{array}$ & $\begin{array}{l}\text { Os estabelecimentos de } \\
\text { formação de professores, os } \\
\text { estágios, os cursos de } \\
\text { reciclagem etc. }\end{array}$ & $\begin{array}{c}\text { Pela formação e pela } \\
\text { socialização profissionais nas } \\
\text { instituições de formação de } \\
\text { professores }\end{array}$ \\
\hline $\begin{array}{l}\text { Saberes provenientes dos } \\
\text { programas e livros didáticos } \\
\text { usados no trabalho }\end{array}$ & $\begin{array}{l}\text { Na utilização das "ferramentas" } \\
\text { dos professores, programas, } \\
\text { livros didáticos, cadernos de } \\
\text { exercícios, fichas etc. }\end{array}$ & $\begin{array}{c}\text { Pela utilização das } \\
\text { "ferramentas" de trabalho, sua } \\
\text { adaptação às tarefas }\end{array}$ \\
\hline $\begin{array}{c}\text { Saberes provenientes de sua } \\
\text { própria experiência na profissão } \\
\text { na sala de aula e na escola }\end{array}$ & $\begin{array}{l}\text { A prática do ofício na escola e } \\
\text { na sala de aula, a experiência } \\
\text { dos pares etc. }\end{array}$ & $\begin{array}{l}\text { Pela prática do trabalho e pela } \\
\text { socialização profissional }\end{array}$ \\
\hline
\end{tabular}

Fonte: Tardif; Raymond (2000)

Percebe-se que os autores destacam as trajetórias pré-profissionais com saberes pessoais provenientes da socialização primária, os saberes da formação escolar, provenientes da época em que eram alunos na educação básica e as trajetórias profissionais com os saberes advindos da formação inicial, das ferramentas pedagógicas como os livros didáticos e da própria prática com a instituição de ensino e sala de aula, englobando uma diversidade de saberes no decorrer do tempo na trajetória profissional do professor. Eles afirmam que:

Os saberes dos professores são temporais, pois são utilizados e se desenvolvem no 
âmbito de uma carreira, isto é, ao longo de um processo temporal de vida profissional de longa duração no qual intervêm dimensões identitárias, dimensões de socialização profissional e também fases e mudanças. A carreira é também um processo de socialização, isto é, um processo de marcação e de incorporação dos indivíduos às práticas e rotinas institucionalizadas das equipes de trabalho [...] saber como viver numa escola é tão importante quanto saber ensinar na sala de aula (TARDIF; RAYMOND, 2000, p. 217).

Consideramos importante deixar claro o que significa "saber" para os autores. Eles atribuem "um sentido amplo que engloba os conhecimentos, as competências, as habilidades (ou aptidões) e as atitudes dos docentes, ou seja, aquilo que foi muitas vezes chamado de saber, de saber-fazer e de saber-ser"(TARDIF; RAYMOND, 2000, p. 212).

Outra perspectiva é a de Ball, Thames e Phelps (2008) que, inspirados nos estudos de Shulman $(1986)^{3}$ teceram um modelo de Conhecimentos Matemáticos para o Ensino, o Mathematical Knowledge for Teaching (MKT). Neste modelo teórico de conhecimentos há duas dimensões, a primeira, do conhecimentos de conteúdo, com três subcategorias, que são: conhecimento comum do conteúdo, conhecimento especializado do conteúdo e conhecimento horizontal do conteúdo; a segunda dimensão, que se refere aos conhecimentos pedagógicos do conteúdo e contém três subcategorias, que são: conhecimento do conteúdo e do aluno, conhecimento do conteúdo e ensino e conhecimento de currículo. Para o presente artigo nos deteremos na dimensão pedagógica do conteúdo, sobre o qual a seguir, definimos sucintamente cada categoria.

O conhecimento de conteúdo e alunos combina o conhecimento matemático e conhecimento dos alunos, com seus prováveis equívocos, dúvidas e possíveis respostas diante do conteúdo matemático. Os professores devem ser capazes de saber o que os estudantes acharão interessante e motivador.

O conhecimento de conteúdo e ensino combina o conhecimento de conteúdos da Matemática e estratégias de ensino, como criar representações para exemplificar o conteúdo ensinado; a pertinência ou não de utilizar um exemplo apresentado pelos alunos; como organizar a apresentação do conteúdo de modo a conhecer quais atividades ajudarão os alunos na aprendizagem e superação de dificuldades sobre o conteúdo, entre outros aspectos.

O conhecimento de conteúdo e currículo significa conhecer o que os documentos oficiais da educação, os livros didáticos e o currículo de um modo geral propõem para o ano escolar que ensina, um importante papel para o planejamento de aula do professor.

\footnotetext{
${ }^{3}$ Como contribuição central dos estudos de Shulman e colaboradores, Ball et al, apontaram a reformulação do estudo do conhecimento do professor, de modo que atendam ao papel do conteúdo no ensino e de forma secundária, representar o entendimento do conteúdo como um tipo especial de conhecimento técnico essencial para a profissão do professor (BALL; THAMES; PHELPS, 2008).
} 
Dessa forma, adequamos o modelo matemático de Ball e colaboradores (2008) para o ensino de Educação Financeira Escolar, tema que, por seu caráter transversal e integrador, admite o trabalho com diversas disciplinas e conteúdos, não se detendo necessariamente à Matemática.

\section{METODOLOGIA}

O presente artigo é de natureza qualitativa, que segundo Minayo "responde a questões muito particulares[...] ela trabalha com o universo de significados, motivos, aspirações, crenças, valores e atitudes, o que corresponde a um espaço mais profundo das relações, dos processos e dos fenômenos" (MINAYO, 2001, p. 21-22).

\section{Campo, sujeitos e instrumentos}

O campo de pesquisa foi uma escola particular em Recife-PE. Os sujeitos são duas professoras que ensinam no $3^{\circ}$ ano do Ensino Fundamental. O instrumento utilizado foi a entrevista semiestruturada. As perguntas que nortearam a pesquisa estão dispostas no Quadro 2.

Quadro 2: Roteiro da entrevista semiestruturada.

\begin{tabular}{|c|c|}
\hline ETAPAS & DESCRIÇÃO \\
\hline $\begin{array}{l}\text { Perfil e experiência } \\
\text { profissional }\end{array}$ & $\begin{array}{l}\text { - } \quad \text { Formação Inicial: } \\
\text { - } \quad \text { Formação continuada: } \\
\text { - } \quad \text { Cursos de pós-graduação: } \\
\text { - } \quad \text { Qutras formaçõal sua idade? } \\
\text { - Há quanto tempo exerce a profissão de professor? } \\
\text { - Onde você trabalha? (informar se escola particular ou pública) } \\
\text { - Em quais etapas de ensino você ministra aula? }\end{array}$ \\
\hline $\begin{array}{l}\text { Conhecimentos } \\
\text { pedagógicos de Educação } \\
\text { Financeira }\end{array}$ & $\begin{array}{l}\text { - Em qual ou quais disciplina(s) você acredita que é possível trabalhar o } \\
\text { - } \quad \text { Ema Educação Financeira? } \\
\text { esse tema? } \\
\text { - Você considera a EF um tema transversal? Por quê? } \\
\text { - Ensinar o sistema monetário e Educação Financeira. Quais as possíveis } \\
\text { - Jelações? } \\
\text { - Já identificou o tema em livro didático? De qual disciplina? Em qual } \\
\text { - Janteúdo? deu aula sobre o tema EF? } \\
\text { - Para saber mais sobre EF para ensinar e para si a quem recorreria? }\end{array}$ \\
\hline
\end{tabular}

Fonte: Própria (2020)

A análise dos resultados foi de cunho interpretativo baseado na teoria MKT de Ball e colaboradores (2008), nos estudos de Tardif e Rayond (2000) e de pesquisadores da EF. 
Foram entrevistadas duas professoras, aqui denominadas de P1 e P2. Ambas são professoras polivalentes em uma escola particular em Recife-PE, lecionando o $3^{\circ}$ ano do Ensino Fundamental. P1 possui Magistério e Licenciatura em História, tem 40 anos de idade e 23 anos de docência. P2 possui os cursos de Magistério e Pedagogia, tem 50 anos de idade e 28 anos de docência. Podemos observar a síntese do perfil das professoras no Quadro 3, a seguir.

Quadro 3: Perfil e experiência profissional das professoras entrevistadas

\begin{tabular}{|c|c|c|}
\hline & Professora 1 & Professora 2 \\
\hline Formação Inicial & $\begin{array}{c}\text { - Magistério } \\
\text { - Licenciatura em História }\end{array}$ & $\begin{array}{c}\text { - Magistério } \\
\text { - Licenciatura em Pedagogia }\end{array}$ \\
\hline Cursos de aperfeiçoamento & $\begin{array}{l}\text { Excelência no atendimento e } \\
\text { secretariado }\end{array}$ & $\begin{array}{l}\text { Preparação de material para } \\
\text { alunos com necessidades } \\
\text { especiais; Cursos de como } \\
\text { trabalhar a História; Jogos } \\
\text { matemáticos na sala de aula; } \\
\text { Alfabetização e letramento. }\end{array}$ \\
\hline Cursos de pós-graduação & - & $\begin{array}{l}\text { Especialização em História de } \\
\text { Pernambuco }\end{array}$ \\
\hline $\begin{array}{lll}\text { Formação } & \text { sobre } & \text { Educação } \\
\text { Financeira } & & \end{array}$ & Não & Sim, uma palestra em 2019 \\
\hline Idade & 40 anos & 50 anos \\
\hline Tempo de profissão & 23 anos & 28 anos \\
\hline Tipo de instituição onde trabalha & Colégio particular & Colégio particular \\
\hline $\begin{array}{l}\text { Quais anos escolares ou etapas de } \\
\text { ensino leciona ou já lecionou e por } \\
\text { quanto tempo }\end{array}$ & $\begin{array}{l}\text { Nos últimos quatro anos } \\
\text { leciona o } 3^{\circ} \text { ano do Ensino } \\
\text { Fundamental. }\end{array}$ & $\begin{array}{l}\text { Nos últimos três anos leciona o } \\
3^{\circ} \text { ano do Ensino Fundamental. }\end{array}$ \\
\hline
\end{tabular}

Fonte: Própria (2020)

É importante esclarecer que optamos por discutir mais amplamente os conteúdos matemáticos que foram mencionados pelas professoras por se aproximar de nosso campo de pesquisa em Educação Matemática. Ressaltamos, ainda, que as entrevistadas algumas vezes optavam por responder de forma integrada as perguntas realizadas, pois, por se tratar de entrevista semiestruturada, assemelhava-se a uma conversa sobre sua prática profissional, visto que sentiam-se mais à vontade em algumas ocasiões ouvindo mais de uma pergunta e optando respondê-las conjuntamente, atendemos as peculiaridades das entrevistadas e por esse motivo não alocaremos cada pergunta seguida de cada reposta. Apresentamos a seguir os resultados e discussões.

\section{RESULTADOS E DISCUSSÕES}

Nesta seção são apresentados os conhecimentos mobilizados pelos professores na entrevista sobre conhecimentos pedagógicos de EF, na qual evidenciam as disciplinas, os conteúdos de Matemática indicados para o trabalho com a EF, se consideram o tema 
transversal e de que forma entendem a transversalidade.

\title{
Conhecimentos Pedagógicos de EF mobilizados pelas professoras entrevistadas sobre disciplinas, conteúdos e transversalidade
}

Apresentamos a seguir excertos de falas das professoras sobre a proposição das disciplinas e conteúdos relacionados à EF.

\begin{abstract}
Pode ser Português, incluindo palavras né? A princípio se eu fosse fazer aula desse conteúdo Educação Financeira, eu faria algo muito chamativo. Então voltando ao produto, porque a gente precisa de um produto né? Então se eu fosse falar sobre água, a compra de água, a escassez da água e valores. Ter o produto em sala, falar da importância desse produto, do valor em dinheiro e social do [produto], falar da importância para a vida, que não se vive sem. E aí falar de valores, falar de subtração, adição, de economia. [Sobre disciplinas] Ciências, Matemática, Português, Biologia, trabalharia em Português a silaba complexa gu. Uma coisa tão simples, mas que abrange tanta coisa. Pode ser em Geografia também, como água no município, por que não? Eu acho que as cinco que eu trabalho, eu acho não, tenho certeza. Português, Matemática, História, Ciências e Geografia. As cinco dá para trabalhar, você pega um conteúdo, Geografia, você pega passagens aéreas, passagens né? De sair de país para outro, de um lugar para outro, trabalha os valores das passagens, o quanto se pode programar (Professora 1).
\end{abstract}

A Professora 1, no excerto acima, cita as disciplinas de Português, Matemática, Ciências, Biologia e História e, embora cite várias disciplinas, expõe algumas possibilidades de tratar o tema de forma interdisciplinar com algumas disciplinas, não incluindo todas as que citou. Quanto à transversalidade da EF afirma que:

Sim, eu considero [transversal] porque ela vai de todas as disciplinas, ela consegue ir a fundo, atravessar ela, sem desmontar nada (Professora 1).

Podemos observar que ela considera que o tema é transversal, pois atravessa todas as disciplinas, demonstrando conhecer o que a expressão significa, embora não demonstre conhecer que esse termo é proposto para o tema por documentos oficiais como a BNCC (BRASIL, 2017) e os Parâmetros Curriculares de Pernambuco - PCPE (PERNAMBUCO, 2019), pois quando perguntamos o porquê da transversalidade, um dos aspectos que poderia ter sido citado, além do que significa ou as possíveis formas de trabalho, seria a presença nos documentos oficiais de educação.

A seguir, apresentamos um excerto de fala da Professora 2 sobre disciplinas e conteúdos em que a EF pode aparecer.

Não tenho muito entendimento de Educação Financeira, a Matemática que seria a base para isso e acredito que História, a história do dinheiro brasileiro, o que você comprava e o que você compra hoje com determinado valor, não sei se seria isso. Em Ciências o desmatamento, os madeireiros que pegam as árvores, que cortam e ganham muito dinheiro em cima disso, destruindo, a gente faz uma ligação pois a Matemática não é só financeiro, porque eles ganham muito dinheiro destruindo o meio ambiente, investimentos maiores do Governo Federal pra evitar o desmatamento, trabalharia o financeiro que tem tal verba para o meio ambiente, tal 
verba para educação, se empregada de forma adequada daria pra suprir o que se precisa na educação, na saúde. Fazendo uma ligação interdisciplinar de História, Ciências e Matemática porque nesse caso aí entra tudo (Professora 2).

A Professora 2 apontou as disciplinas Matemática, Ciências e História e destacou temas relacionados à cidadania, evidenciando possíveis abordagens interdisciplinares. No que concerne à disciplina de Matemática e ao tema cidadania, corrobora a proposição de alguns países como Portugal e Reino Unido. Pois, de acordo com Soares (2017) o Reino Unido tem sua estratégia de EF criada desde 2003, tendo o ensino de EF como facultativo nos currículos escolares desde 2001 e de acordo com o site Todos Contam $^{4}$, a EF passou a ser obrigatória nos currículos escolares do Reino Unido a partir de 2013, nas disciplinas de Matemática e Cidadania. De modo similar, Portugal instituiu sua estratégia de EF em 2012, por meio do Decreto $n^{\circ} 139 / 2012$ para que o tema seja trabalhado de forma transversal na educação para a cidadania, de frequência optativa segundo o decreto. No entanto, Domingos e Santiago (2016), pesquisadores e residentes do país, indicam que o tema pode ser trabalhado na área da Educação Matemática de forma geral e na disciplina de Matemática de forma particular.

Quanto à transversalidade, a Professora 2 considera o tema transversal pela capacidade de abordar vários elementos e conjecturamos, baseadas em suas falas, que ela entenda que outras disciplinas também podem ser abordadas conjuntamente. Sobre isso, podemos ver sua explicação no fragmento a seguir.

Eu acredito que sim. Porque dentro da Educação Financeira você trabalha consumo
consciente, solidariedade, quando fala da doação você tá pensado no próximo,
quando fala para não procurar fazer dívidas que você não possa sanar depois. Então
acredito que trabalhe vários pontos, é tema transversal que trabalha muita coisa que
se a gente for se aprofundar trabalha tanta coisa que a gente nem imagina
(Professora 2).

A Professora 2 também não explicita se conhece que a transversalidade do tema é proposta pelos documentos oficiais. Observou-se que ela considerou diversos elementos não matemáticos, assim como considerou diversas atitudes que podem ser refletidas no trabalho com a EF, incluindo uma abordagem coletiva, quando ela coloca sobre consumo consciente, solidariedade, doações. Diferentemente de outras abordagens, a EFE tem o intuito de estimular a reflexão do estudante sobre diversos aspectos no que se refere a recursos finitos e a tomadas de decisões que têm repercussões maiores, abrangendo os que estão ao nosso redor.

A partir do que as professoras apresentaram, sintetizamos no Quadro 4 as disciplinas e conteúdos de Matemática evidenciados por elas na entrevista.

${ }^{4}$ https://www.todoscontam.pt/pt-pt/noticias/educacao-financeira-entra-no-curriculo-escolar-do-reino-unido 
Quadro 4: Disciplinas e Conteúdos de Matemática indicados pelas professoras entrevistadas na abordagem da Educação Financeira

\begin{tabular}{|l|l|l|}
\hline PROFESSORAS & \multicolumn{1}{|c|}{ DISCIPLINAS } & \multicolumn{1}{|c|}{$\begin{array}{c}\text { CONTEÚDOS DE } \\
\text { MATEMÁTICA }\end{array}$} \\
\hline PROFESSORA 1 & $\begin{array}{l}\text { Ciências, Matemática, Português, } \\
\text { Biologia, Geografia e História }\end{array}$ & $\begin{array}{l}\text { subtração, adição, economia, } \\
\text { divisão, termos quociente, } \\
\text { dividendo parcelas, } \\
\text { decomposição de números }\end{array}$ \\
\hline PROFESSORA 2 & Matemática, Ciências e História & $\begin{array}{l}\text { divisão, multiplicação, significado } \\
\text { do termo parcela, sistema } \\
\text { monetário brasileiro, grandezas e } \\
\text { medidas. }\end{array}$ \\
\hline
\end{tabular}

Fonte: Própria (2020)

Diante dos conteúdos da Matemática elencados pelas professoras, percebe-se as unidades temáticas de Números, Álgebra, e Grandezas e Medidas. Aparece ainda, aspectos de economia, citados pela Professora 1. Percebe-se que ela relacionou o tema com princípios econômicos, assim como fez a Professora 2, a qual explicou a aplicação de elementos econômicos se referindo a valores monetários e sociais, exemplificando as disciplinas em que e como poderiam ser abordadas. Já a Professora 1 cita possíveis atividades como o trabalho com a água ou sobre passagens aéreas. conjecturamos que as Professora 1 e 2 formularam possibilidades de trabalho com o tema a partir de suas experiências docentes. Destacamos que nenhuma das duas docentes recebeu formação sistemática sobre o tema de EFE, apenas a Professora 2 já havia assistido a uma palestra sobre finanças pessoais de uma iniciativa privada.

Buscou-se evidenciar o Conhecimento Curricular das professoras, assim como o Conhecimento de EF e Ensino, quando fazem a contextualização de suas respostas. Foi possível perceber que alguns conhecimentos evidenciado pelas docentes emana da prática pedagógica, destacando dessa forma os achados de Tardif e Raymond (2000), que são os "Saberes provenientes da história de vida individual, da sociedade, da instituição escolar, dos outros atores educativos, dos lugares de formação etc" (TARDIF; RAYMOND, 2000, p. 215). Sobre os documentos oficiais, não houve nenhuma menção, não se sabe se por desconhecimento ou por esses documentos ficarem em "segundo plano" em suas práticas diárias. Inferimos que as professoras possuam o conhecimento curricular que está nos documentos oficias, por meio das atividades e conteúdos inseridos nos livros e materiais didáticos, que a partir de sua prática e larga experiência em sala de aula conseguem mencionar disciplinas e conteúdos que se relacionem ao tema e ao ano que lecionam.

O estudo de Silva, Pessoa e Carvalho (2019), aponta que pedagogas confundem o ensino do sistema monetário com o de Educação Financeira. Como mencionamos anteriormente, embora possam ser trabalhados juntos, o ensino de EF é diferente do ensino do 
sistema monetário, pois EF abrange diversos conteúdos e áreas do conhecimento e o sistema monetário versa sobre aspectos da moeda nacional e alguns de seus usos. Como será que as professoras entrevistadas os consideram? A seguir, discutiremos sobre como as professoras percebem as relações entre sistema monetário e EF.

\begin{abstract}
extremamente importantes, porque um indivíduo endividado ele é prejuízo para sociedade. Você vai conhecer o dinheiro, porque as crianças têm essa dificuldade né? A partir de conhecer as cédulas, as moedas é que elas vão poder lidar com o dinheiro, a partir daí saber juntar, saber o quanto vai pagar, o quanto vem de troco, entender parcela (PROFESSORA 1).
\end{abstract}

Importantíssimo nos dias atuais. Se você trabalha uma matemática aliada a educação é pra vida. Como eu falei, as questões que vem no livro, que a gente pode até ampliar mas o corre corre é tão grande, pra dar conta de conteúdos termina a gente não focando e fica mais a matemática de sala de aula que a criança precisa saber, compreender as operações fundamentais. E não aquela matemática ou educação que ela leva pra vida, que ela vai um dia precisar usar e de repente lembrar, poxa isso foi trabalhado desde que eu estava nas séries iniciais (PROFESSORA 2).

Sobre sistema monetário e EF a Professora 1 fala que é importante porque algumas crianças têm dificuldade de identificar e a partir disso trabalhar conceitos de juntar, troco, entender o termo parcela, o quanto vai pagar. Para a P1, o trabalho ajudaria a aprender a lidar com o dinheiro. Nessa situação, a professora não enfatiza apenas as operações matemáticas, mas aborda outros elementos como o lidar com o dinheiro, o que evidencia, mesmo que de forma incipiente, a diferença entre o ensino do sistema monetário e a EF. Conjecturamos que a professora entenda como complementares. No que concerne a atividades identificadas nos livros didáticos, a Professora 1 afirma já ter visto, mas que não tinha parado para pensar nessa abordagem. Ela recorda que o livro didático que utilizava no ano anterior falava sobre o assunto, que abordava sobre o valor das coisas, planejamento no contexto familiar, como planejar uma viagem, por exemplo.

De forma semelhante, a Professora 2 diz que encontra o tema nos livros didáticos na abordagem do conteúdo de sistema monetário com foco no ensino das operações, e mesmo que apareçam situações de venda, o foco dado é nas operações matemáticas, embora reconheça que há diferenças entre o ensino do sistema monetário e EF. No Quadro 5 observamos a síntese de conhecimentos de EF evidenciados pelas professoras na entrevista.

Quadro 5: Conhecimento de situações envolvendo Educação Financeira indicados pelas professoras entrevistas

\begin{tabular}{|c|l|l|}
\hline $\begin{array}{c}\text { CONHECIMENTO DE } \\
\text { SITUAÇÕES ENVOLVENDO } \\
\text { EF }\end{array}$ & \multicolumn{1}{|c|}{ PROFESSORA 1 } & \multicolumn{2}{|c|}{ PROFESSORA 2 } \\
\hline Transversalidade & Sim & Sim \\
\hline EF e Sistema Monetário & $\begin{array}{l}\text { Complementares com foco em } \\
\text { operações } \\
\text { matemáticas }\end{array}$ & $\begin{array}{l}\text { Complementares com foco em } \\
\text { operações } \\
\text { matemáticas }\end{array}$ \\
\hline
\end{tabular}




\begin{tabular}{|l|l|l|}
\hline & (pontuando os livros didáticos) & (pontuando os livros didáticos) \\
\hline $\begin{array}{l}\text { Já encontrou o tema em livro } \\
\text { didático }\end{array}$ & Sim & Sim \\
\hline Já deu aula sobre o tema & Não & Não \\
\hline $\begin{array}{l}\text { Para saber mais sobre EF para } \\
\text { ensinar e para si }\end{array}$ & Internet, Pesquisadora & $\begin{array}{l}\text { Curso universitário, Consultor } \\
\text { financeiro }\end{array}$ \\
\hline
\end{tabular}

Fonte: Própria (2020)

A partir dos dados, é possível perceber que as professoras apresentam o Conhecimento de EF e Ensino, remetendo-nos à teoria de Ball e colaboradores (2008), a qual adaptamos para a EF, quando reconhecem a diferença entre o ensino de EF e do sistema monetário. As professoras, apesar de reconhecerem a diferença e a importância da EF, não aplicam em sala de aula, segundo elas próprias. Qual ou quais seriam os motivos para que a EF não seja abordada em sala por essas professoras?

De acordo com a Professora 1 seria por falta de conhecimento e formação para tratar o assunto e a Professora 2 enfatiza que não os aborda em sala porque o tempo pedagógico é voltado para atender as exigências dos conteúdos, como ela argumenta no trecho a seguir:

as questões que vêm no livro, que a gente pode até ampliar mas o corre-corre é tão grande pra dar conta de conteúdos, termina a gente não focando e fica mais a Matemática de sala de aula que a criança precisa saber, compreender as operações fundamentais (Professora 2).

As professoras demonstram mais conhecimentos de EF do que supunham no início da entrevista. Reconhecemos que essa temática ainda é relativamente nova como obrigatória em sala de aula e pouco ou nada abordada em formações iniciais e continuadas de professores.

\section{CONCLUSÕES}

As questões que nortearam o estudo foram: $\mathrm{Na}$ visão de professores, em quais disciplinas e conteúdos a EF pode ser abordada? Os professores conhecem a transversalidade da temática EF e como desenvolvê-la em sala de aula? Para responder a essas questões, buscamos analisar Conhecimentos Pedagógicos de Educação Financeira de professores que ensinam Matemática no $3^{\circ}$ ano do Ensino Fundamental. Especificamente objetivamos analisar qual ou quais disciplinas podem, na visão de professores, trabalhar o tema EF; e discutir sobre a transversalidade do tema e as possíveis relações com conteúdos matemáticos.

Foram realizadas entrevistas com duas professoras que ensinam no $3^{\circ}$ ano do Ensino Fundamental em uma escola particular de Recife-PE. Como principais resultados, observamos que as professoras pareciam desconhecer os documentos oficiais no que tange a temática de EF. No entanto, utilizaram a experiência docente para relacionar possíveis conteúdos e 
disciplinas ao tema, o que nos remete ao conhecimento de conteúdo e ensino, quando escolhem abordagens apropriadas para o conteúdo; conhecimento de conteúdo e aluno, quando procuram adequar o ensino à realidade vivenciada pelo aluno; e ainda, o conhecimento curricular, através do reconhecimento de conteúdos e atividades adequadas ao ano escolar por meio de livros e materiais didáticos escolares.

Quanto ao ensino do sistema monetário e EF, a Professora 1 demonstra entender como complementares e reconhece a importância do conteúdo de sistema monetário, pois alguns estudantes apresentam dificuldades sobre o assunto. A Professora 2 reconhece a diferença e aponta que quando trabalhado em livro didático, o foco maior é para a resolução de elementos matemáticos. Sobre as disciplinas e conteúdos de Matemática apontados pelas professoras, aparenta ser de sua prática pedagógica, remetendo-nos aos saberes da experiência discutidos por Tardif e Raymond (2000).

Inicialmente, na análise dos resultados, conjecturamos que a categoria objetiva seria o Conhecimento de EF e Currículo, pois estariam diretamente ligados ao que já estava posto nos documentos oficiais, no entanto, a partir da análise das entrevistas com as professoras, embora elas não citem nada sobre os documentos oficiais, nem sobre a obrigatoriedade do tema desde 2017, a partir de suas experiências de prática em sala de aula, conseguem correlacionar disciplinas, conteúdos e adequar a cada ano escolar, o que nos remete ao Conhecimento de Conteúdo e Ensino, assim como o Conhecimento de Conteúdo e Aluno e, além disso, remetenos ao saber da experiência descrito por Tardif e Raymond (2000).

Diante disso, salientamos a importância da formação de professores no intuito de ampliar e trazer à consciência os Conhecimentos para o Ensino de uma EF crítica, reflexiva e contextualizada. Dada a importância da temática, além da formação de professores, é necessário formar coordenadores pedagógicos para trabalharem com os seus professores e viabilizarem as ações. A partir dos dados coletados e analisados, salientamos também a importância de se aproveitar nas formações os ricos conhecimentos que os professores apresentam.

\section{REFERÊNCIAS}

BALL, Deborah; THAMES, Mark Hoover; PHELPS, Geoffrey. Content knowledge for teaching what makes it special? Journal of teacher education, 59(5), 389-407, 2008.

BRASIL. Base Nacional Comum Curricular, Brasília: MEC/SEF, 2017. 
BRASIL. BRASIL: Implementando a Estratégia Nacional de Educação Financeira. 2010. Disponível

em: https://www.bcb.gov.br/pre/pef/port/Estrategia_Nacional_Educacao_Financeira_ENEF.p dfacesso em 13/05/2019.

BRASIL. Decreto 10.393 de junho de 2020. Institui a nova Estratégia de Educação Financeira - ENEF e o Fórum Brasileiro de Educação Financeira - FBEF. Brasília: DOU - Diário

Oficial da União. Publicado no D.O.U de 09 de junho de 2020. Disponível em http://www.planalto.gov.br/ccivil_03/_Ato2019-2022/2020/Decreto/D10393.htm acesso em $10 / 10 / 2020$.

DOMINGOS, António; SANTIAGO, Ana. Conceções e Práticas de Professores de Matemática sobre Educação Financeira. Revista de Educação, Ciências e Matemática v.6 n.3 set/dez 2016.

MINAYO, Maria. Cecília. Pesquisa Social. Teoria, método e criatividade. 18 ed. Petrópolis: Vozes, 2001. Disponível em: http://www.faed.udesc.br/arquivos/id_submenu/1428/minayo_2001.pdf

Acesso em: 08/09/2020.

OECD. Quem somos. OECD, 2019. Disponível em: https://www.oecd.org/about/ Acesso em outubro de 2019.

PESSOA, Cristiane. Educação Financeira: $O$ que tem sido produzido em mestrados e doutorados defendidos entre 2013 e 2016 no Brasil? In: CARVALHÊDO, J.; CARVALHO, M. V.; ARAUJO, F. (orgs.) Produção de conhecimentos na Pós-graduação em educação no nordeste do Brasil: realidades e possibilidades. Teresina: EDUPI, 2016. Disponível em: https://www.scribd.com/document/389378011/ARAUJO-producao-de-conhecimento-pdf

Acesso em 08/09/2020

PERNAMBUCO. Secretaria de Educação e Esportes. Currículo de Pernambuco: Caderno de Matemática e Ciências, 2019.

PORTUGAL. Decreto-Lei n. ${ }^{\circ}$ 139, de 5 de julho de 2012. Estabelece os princípios orientadores da organização e da gestão dos currículos, da avaliação dos conhecimentos e capacidades a adquirir e a desenvolver pelos alunos dos ensinos básico e secundário. Diário da República, 1. ${ }^{\text {a }}$ série- N. ${ }^{\circ}$ 129, Ministério da Educação e Ciência,5 de julho de 2012.

TODOS CONTAM. Educação Financeira entra no Currículo Escolar do Reino Unido. Todos Contam, 2013. https://www.todoscontam.pt/pt-pt/noticias/educacao-financeira-entrano-curriculo-escolar-do-reino-unido Acesso em 10/09/2020..

SHULMAN, Lee. Those who understand: Knowled gegrowth in teaching. Educational researcher, 15(2), 4-14, 1986.

SOARES, Fabrício. Pereira. Os debates sobre a Educação Financeira em um contexto de financeirização da vida doméstica, desigualdade e exclusão financeira. Tese de Doutorado. PUC, Rio de Janeiro, 2017. 
TARDIF, Maurice. RAYMOND, Danielle. Saberes, tempo e aprendizagem do trabalho no magistério. Educação \& Sociedade, ano XXI, n 209 o 73, Dezembro de 2000.

SILVA, Arlam; PESSOA, Cristiane.; CARVALHO, Liliane. Educação Financeira em aulas de Matemática: “o que eu vejo é o sistema monetário!". Anais do XIII Encontro Nacional de Educação Matemática - XIII ENEM, Cuiabá-MT, 14 a17 de julho de 2019.

SILVA, Amarildo; POWELL, Arthur. Um Programa de Educação Financeira para a Matemática Escolar da Educação Básica. Anais do XI Encontro Nacional de Educação Matemática- XI ENEM, Curitiba-PR, 18 a 21 de julho de 2013. 